\title{
Familial multiple lateral telangiectatic nevi (port-wine stains or nevi flammei)
}

Pasyk KA. Familial multiple lateral telangiectatic nevi (port-wine stains or nevi flammei)

Clin Genet 1992: 41: 197-201.

Two families with multiple lateral telangiectatic nevi (LTN) (port-wine stains or nevi flammei) in various areas of the body in two and three generations are presented. In the second family, some members in addition to LTN also had superficial (strawberry) hemangiomas and hemangiomalike venous malformations. The pedigrees of these families indicate autosomal dominant inheritance of multiple LTN.

\author{
Krystyna A. Pasyk \\ Section of Plastic and Reconstructive Surgery, \\ University of Michigan School of Medicine, Ann \\ Arbor, Michigan, USA
}

Key words: familial hemangioma-like venous malformations - tamilial multiple capillary malfosmations - familial multiple lateral telanglectatic nevi - familial multiple nevi flammei - familial multiple port-wine stains - familial superficial (strawberry) hemangiomas - vascular birthmarks Krystyna A. Pasyk, Section of Plastic and Reconstructive Surgery, University of Michigan Med. Center, Ann Arbor, Michigan 481090340, U.S.A.

Received 19 June, revised 30 September, accepted for publication 16 October 1991
Congenital capillary malformations belong to the group of cellularly adynamic vascular malformations (Pasyk et al. 1984a, Pasyk 1987) and are present at birth in two main types: 1) medial telangiectatic nevus (MTN), also known as salmon patch, angel's kiss, stork bite, etc., and 2) lateral telangiectatic nevus (LTN), more popularly called port-wine stain or nevus flammeus, neither of which are scientific or medical terms.

The MTN appears in 50 to $74 \%$ of all newborn infants (Bettley 1940, Jacobs \& Walton 1976, Osburn et al. 1987) as pink-red or light violet, irregular maculae or patches primarily on the medial part of glabello-frontal, occipito-nuchal or lumbosacral areas. These vascular discolorations gradually disappear in about $50 \%$ of cases during the first years of life (Hurwitz 1981). In adults they were found as persistent MTN, especially in the occipito-nuchal region in $57.5 \%$ (van Baar et al. 1989).

The LTN, however, is found in 0.3 to $1 \%$ of neonates (Jacobs \& Walton 1976, Pratt 1953, Merlob et al. 1981) as a flat pink-red to purple macula, usually on the face in the distribution of the trigeminal nerve. The lesion may very rarely cross the midline (Rook 1972), be located bilaterally and symetrically on the face (Schnyder 1954) and extremities (Rook 1972). The LTN may occur anywhere on the body and is usually asymmetrical and unilateral with a dermatomal pattern, but bilateral nonsymmetric distribution on the trunk has also been reported (Wilkin et al. 1979). The LTN, however, rarely appear in multiple areas of the body. The lateral type of telangiectatic nevi have no tendency to fade, and they persist throughout life.

Both types of congenital telangiectatic nevi exhibit mature, ectatic capillaries with flat endothelium in the dermis, primarily in the superficial plexus. In the case of MTN, however, it appears that a defect in maturation of cutaneous sympathetic innervation occurs (Rosen \& Smoller 1987). For LTN, Hasegawa \& Yasuhara (1979) have suggested that developmental anomalies of vasomotor nerve cells derived from neural crest give rise to these vascular malformations. Kitamura et al. (1981), on the basis of ultrastructural studies of LTN, concluded that it is the loss of peripheral nervous elements in the perivascular region that is the basis of this disorder. Smoller \& Rosen (1986) in their elegant immunohistopathologic studies documented significantly decreased nerve density in the perivascular tissue in the lateral type of telangiectatic nevus. These authors suggest that alterations in innervation, and especially loss of perivascular sympathetic neurons, cause dysfunction in vasoconstriction leading to vasodilatation. This concept was recently confirmed by Lanigan \& Cotterill (1990), who observed in LTN reduced vasoactive responses to vasodilating and vasoconstricting stimuli. The cause of these disorders, however, is still unclear.

According to Koblenzer (1970), LTN appears 


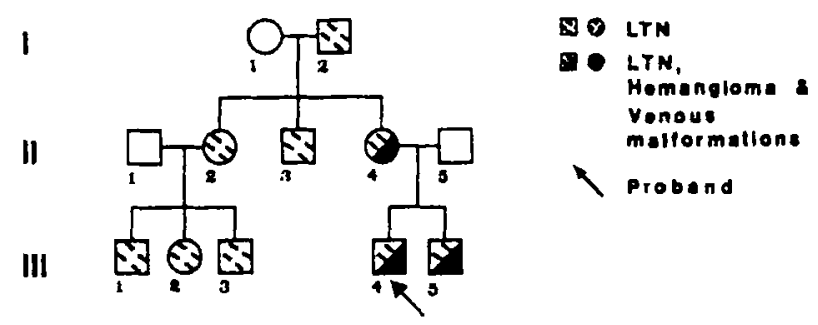

Fig. I. Pedigree of Family 1 with multiple lateral telangiectatic nevi (port-wine stains).

randomly in the population without convincing evidence that it is inherited. Multiple LTN, however, have been reported in a few families (Shelley \& Livingood 1949, Kaplan et al. 1976, Zaremba et al. 1979, Mercer et al. 1978, Shuper et al. 1984).

Two additional families with the lateral type of telangiectatic nevi that appeared in numerous locations on the body are presented here. Some members of the second family also had superficial (strawberry) hemangiomas and hemangioma-like venous malformations. Multiple LTN in these families show an autosomal dominant mode of transmission.

\section{Description of tamilies}

\section{Family 1}

The proband (I-2 in the pedigree shown in Fig. 1), a 33-year-old female, was referred to the Laser Clinic for treatment of red spots on the left leg. These lesions had not changed in size or color since birth. During examination numerous reddish macules from $0.5 \times 1 \mathrm{~cm}$ to $1 \times 2.5 \mathrm{~cm}$ in size were seen dispersed on the left leg. The remainder of the physical examination was unremarkable.

The proband's 7-year-old daughter (II-I) was born with a few flat, red patches dispersed on the trunk and one red spot on the neck. All these vascular lesions, approximately $1 \times 2 \mathrm{~cm}$ in size, are still visible. The child was otherwise healthy.

The proband's 5-year-old son (II-2), had also had red spots approximately 1 to $2 \mathrm{~cm}$ in diameter on the upper left eyelid, the left side of the neck and left thigh since birth. Routine, pediatric examination did not show any other abnormalities.

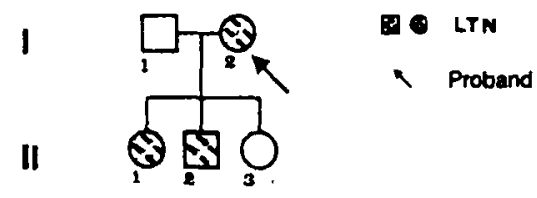

Fig. 2. Pedigree of Family 2 with multiple lateral telangiectatic nevi, superficial (strawberry) hemangiomas, and hemangiomalike venous malformations.

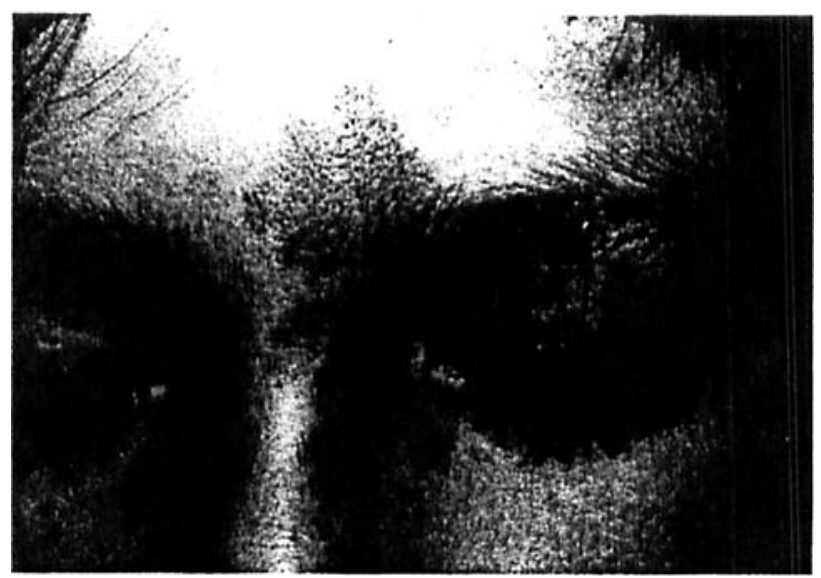

Fig. 3. Proband of Family 2 (III-4), a 7-year-old boy with lateral telangiectatic nevus on his face. Note small pigmented nevus on left side of forehead.

\section{Family 2}

The proband was a 7-year-old male (III- -4 in the pedigree shown in Fig. 2) delivered by $\mathrm{C}$-section. He was brought by his mother for evaluation of various vascular malformations he has had since birth. During examination, red, macular, well-demarcated areas on the left side of his nasal bridge, the left upper eyelid, and the forehead were seen (Fig. 3). Dilated blood vessels were also present on the medial conjunctiva and sclera of the left eye. Several vascular macules were present on the right

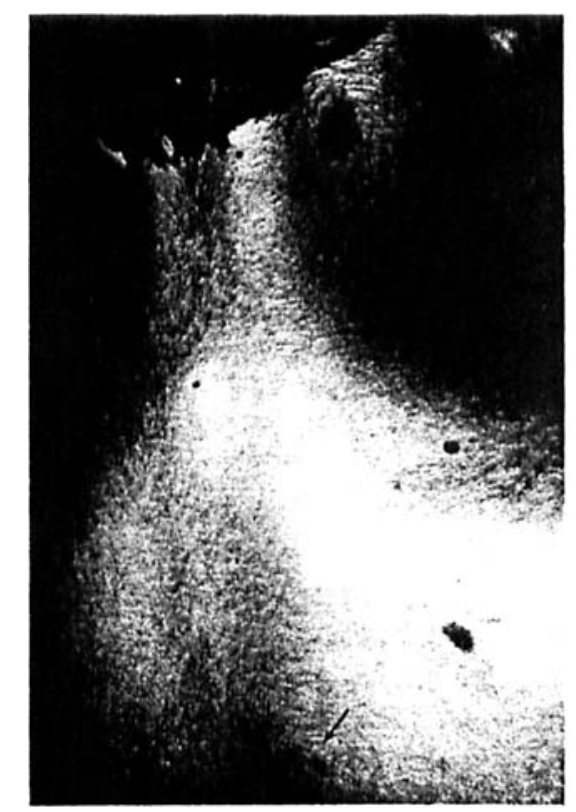

Fig. 4. The same boy (III-4) as in Fig. 3 with lateral telangiectatic nevi and pigmented nevi on right side of neck and back. Arrow indicates involuting superficial (strawberry) hemangioma. 


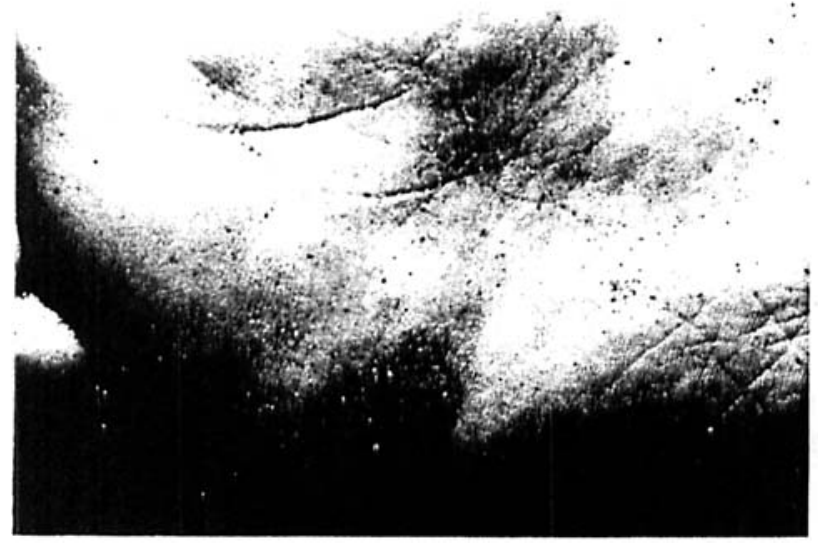

Fig. 5. Lateral telangiectatic nevus on right foot of proband of Family 2 (III-4).

side of the neck, the trunk, the left arm and the left thigh, measuring approximately $1 \times 2 \mathrm{~cm}$ to $1.5 \times 3 \mathrm{~cm}$. An irregular, raised red area, $4 \mathrm{~cm}$ in diameter, with a scar consistent with a resolving superficial (strawberry) hemangioma was present on the mid-back (Fig. 4). On the right foot there was a macular, erythematous patch $2 \times 3.5 \mathrm{~cm}$ in size (Fig. 5). Moreover, the child had numerous small pigmented nevi on his body. He had also had a few asthmatic episodes. During periodical ophthalmologic examinations there was no sign of glaucoma.

The proband's 6-year-old brother (III-5) was also born with vascular malformations. During examination he had a 2 to $3 \mathrm{~cm}$ soft, compressible mass on the left lower lip (probably a deep hemangioma) and an erythematous mass, $1.8 \mathrm{~cm}$ in diameter, on the back with a white scar in the center consistent with an involuting superficial (strawberry) hemangioma. On the left arm, forearm and hand, flat, red spots measuring $0.5 \times 0.7$ $\mathrm{cm}$ and $1 \times 2 \mathrm{~cm}$ were present (Fig. 6).

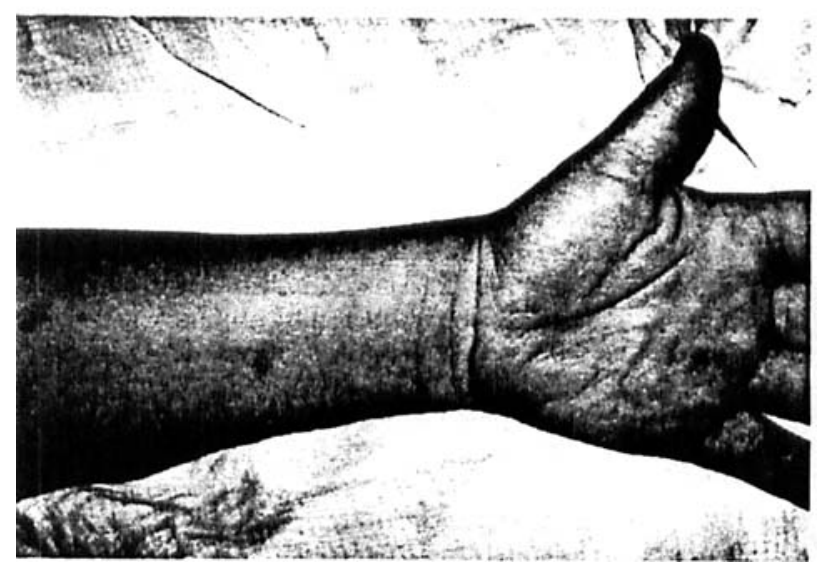

Fig. 6. Six-year-old boy of Family 2 (III-5) with a few lateral telangiectatic nevi on left forearm and hand.

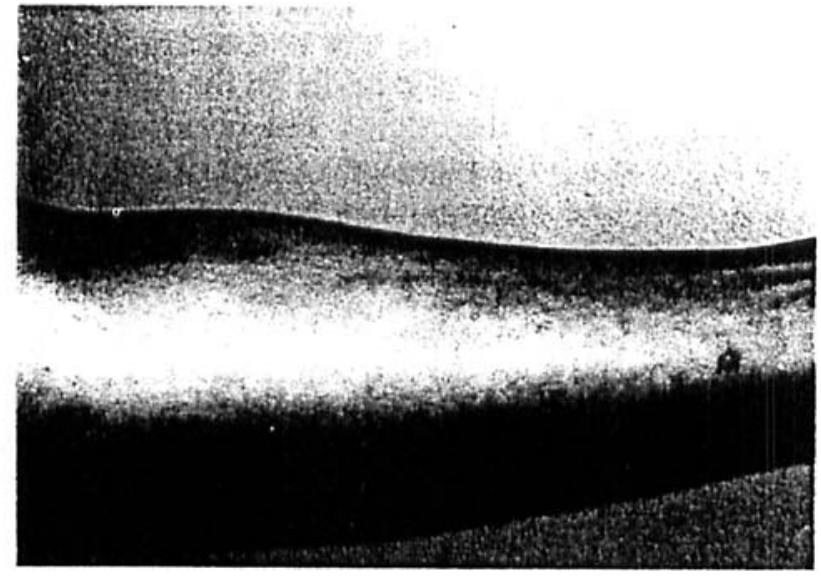

Fig. 7. Case II-4 of Family 2. Mother of above two boys with lateral telangiectatic nevi on right forearm.

The proband's mother (II-4) had had red patches and small pigmented nevi on her body since birth. At examination, besides the pigmented nevi, there were a few dispersed small ( 1 to $2 \mathrm{~cm}$ in diameter), flat, red macules on the trunk and extremities (Fig. 7). On the mid-back there was a red spot approximately $5 \times 8 \mathrm{~cm}$ in size with a soft mass in the deeper part of this lesion (Fig. 8).

Numerous members of the proband's family (Family 2), i.e., a grandfather (I-2), an aunt (II-2), an uncle (II-3), and three cousins (III-1, III-2, III3 ), had also had pink or red patches on various areas of their bodies since birth.

\section{Discussion}

The LTN has very rarely been reported as an inherited entity. In 1913, Benedict described a family in which both mother and daughter had LTN on the right chest, arm, shoulder, and neck. I myself

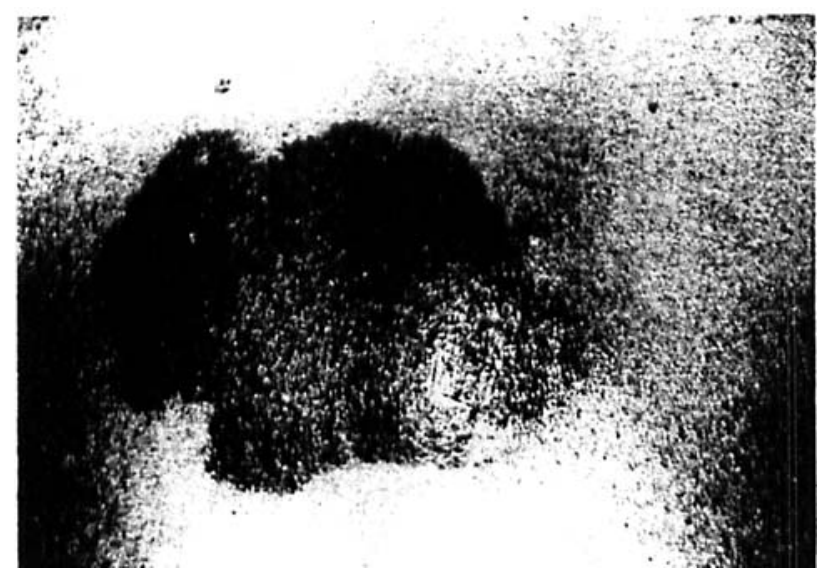

Fig. 8. Case II-4 of Family 2. Lateral telangiectatic nevus on the back and hemangioma-like venous malformations beneath the lateral telangiectatic nevus. 
have treated, with the argon laser, a mother with LTN on the left side of the face and her daughter with a similar telangiectatic nevus on the right side of the face (unpublished data). The occurrence of LTN in phacomatosis pigmentovascularis type IVa in a mother and daughter has been described by Hasegawa \& Yasuhara (1985). Multiple LTN have been reported by Shelley \& Livingood (1949) in a family in which 12 members had numerous vascular malformations on various areas on the skin in four generations. Kaplan et al., in 1976, presented a family with multiple LTN in six members in three generations. Among them were a mother and daughter with multiple LTN; the daughter also had an intraspinal (T12-L5) arteriovenous malformation. A similar family with multiple LTN and arteriovenous malformations of the spinal cord (Cobb syndrome) in one member was described by Mercer et al. (1978). Zaremba et al. (1979) examined a family with multiple LTN in various areas of the body together with intracranial and intraspinal (C6-Tl) arteriovenous malformations. There were four affected members in three generations. This condition was transmitted as an autosomal dominant trait. Shuper et al. (1984) described a family with multiple LTN occurring in nine members, including non-identical twins. In this family autosomal dominant inheritance was confirmed.

The coexistence of LTN, cavernous hemangiomas, and intraspinal arteriovenous malformations has also been observed in a few families (Kufs 1928, Nova 1979, Foo et al. 1980a, b).

Our two families, with numerous LTN disseminated on the body, did not show the presence of any vascular malformations in the central nervous system. It is interesting that some affected members of the Family 2 also had superficial (strawberry) hemangiomas in the involuting stage and hemangioma-like venous malformations.

The occurrence of MTN in families has also been reported (Shafer \& Doig 1955, Zumkeller 1957, Merlob \& Reisner 1985, Selmanowicz 1968, Tan 1972, Nova 1979, Esterly 1987, Mulliken 1988, Pasyk et al. in preparation). Other familial vascular malformations appearing in several generations were described by numerous authors (McIntosh 1957, Riley \& Smith 1960, Clark 1970, Tabor \& Wyatt 1970, Trell et al. 1972, Ide et al. 1974, Marriott et al. 1975, King et al. 1977, Barre et al. 1978, Goldberg et al. 1979, Snead et al. 1979, Zonana et al. 1976, Hayman et al. 1982, Higginbottom \& Schultz 1982, Wertelecki et al. 1982, Pasyk et al. 1984b, Mitchels et al. 1985, Hurst \& Baraitser 1988, Battoni et al. 1990, Gangemi et al. 1990, Nakagawa et al. 1990, Watson et al. 1990).

In the vast majority of familial vascular malformations reported in the literature, the pattern of inheritance shows an autosomal dominant mode of transmission with high penetrance. More studies are needed on the familial incidence of vascular malformations. They might give information about the proportion of familial cases, eventual clinical differences between familial and "sporadic" cases and differences in sex expression and transmission. They might also help to find the genetic defect(s) that lead to these disfiguring and very often devastating lesions.

\section{Acknowledgaments}

This research was supported by the National Vascular Malformations Foundation.

Presented in part at the Dr. Reed O. Dingman Society Research Meeting. Ann Arbor, Michigan, June 1990.

\section{Rotorences}

Barre RG. Suter GS. Rosenblum WI. Familia! vascular malformation or chance occurrence? Neurology (Minneap.) 1978: 28: 98-100.

Battoni F, Canevini MP, Canger R, Orzalesi N. Twin vessels in familial retinal cavernous hemangioma. Am J Ophthalmol 1990: 109: 285-289.

Benedict $H$. Heredodegeneration und postdiphtherische Lahmung. Dtsch Z Nervenh 1913: 43: 492.

Bettley FR. Erythema nuchae. $\mathrm{Br} J$ Dermatol 1940: 52: 363-370.

Clark JV. Familial occurrence of cavernous angiomata of the brain. J Neurol Neurosurg Psychiatry 1970: 33: 871-876.

Esterly NB. Cutaneous hemangiomas, vascular stains, and associated syndromes. Curr Probl Pediatr 1987: 17: 1-69.

Foo DY, Chang C, Rossier AB. Spontaneous cervical epidural haemorthage, anterior cord syndrome and familial vascular malformation: case report. Neurology 1980a: 30: 308-311.

Foo DY, Chang C, Rossier AB. Letter to the Editor. Neurology 1980b: 30: 1253-1254.

Gangemi M, Maiuri F, Donati P, Cinalli G, De Caro M, Sigona L. Familial cerebral cavernous angiomas. Neurol Res 1990: 12: 131-136.

Goldberg RE, Pheasant TR, Shields JA. Cavernous hemangioma of the retina. A four-generation pedigree with neurocutaneous manifestations and an example of bilateral retinal involvement. Arch Ophthalmol 1979: 97: 2321-2324.

Hasegawa Y, Yasuhara M. A variant of phacomatosis pigmentovascularis. Skin Res 1979: 21: 178-186.

Hasegawa Y, Yasuhara M. Phacomatosis pigmentovascularis Type IVa. Arch Dermatol 1985: 121: 651-655.

Hayman LA, Evans RA, Ferrell RE, Fahr LM, Ostrow P. Riccardi VM. Familial cavernous angiomas: natural history and genetic study over a S-year period. Am J Med Genet 1982: 11: 147-160.

Higginbottom MC, Schultz P. The Bannayan syndrome: an autosomal dominant disorder consisting of macrocephaly, lipomas, hemangiomas, and risk for intracranial tumors. Pediatrics 1982: 69: 632-634.

Hurst J, Baraitser M. Hereditary neurocutaneous angiomatous malformations: autosomal dominant inheritance in two families. Clin Genet 1988: 33: 44-48.

Hurwitz S. Vascular disorders of infancy and childhood. In: Clinical pediatric dermatology. Philadelphia: W. B. Saunders Company, 1981: 194.

Ide $\mathrm{CH}$, Holt R, Holt JE. Familiares Vorkommen von kongenit- 
aler generalisierter Hamangiomatose. Klin Mbl Augenheilk 1974: 165: 644-646.

Jacobs AH, Walton RG. The incidence of birthmarks in the neonate. Pediatrics 1976: 58: 218-222.

Kaplan P, Hollenberg RD, Fraser FC. A spinal arteriovenous malformation with hereditary cutaneous hemangiomas. Am J Dis Child 1976: 130: 1329-1331.

King CK, Lourien EW, Reiss J. Central nervous system arteriovenous malformations in multiple generations of a family with hereditary hemorrhagic telangiectasia. Clin Genet 1977: 12: 372-378.

Kitamura W, Iwai M, Sakamoto K. A case of phacomatosis pigmentovascularis. Rinsho Dermatol 1981: 35: 399-405.

Koblenzer PJ. Skin. In: Goodman RM, ed. Genetic disorders of man. Boston: Little Brown \& Co, 1970: 265-312.

Kufs $H$. Uber heredofamiliare Angiomatose des Gehims und der Retina, ihre Beziehungen zu einander und zur Angiomatose der Haut. Z Gesamte Neurol Psych 1928: 113: $651-686$.

Lanigan SW, Cotterill JA. Reduced vasoactive responses in port wine stains. Br J Dermatol 1990: 122: 615-622.

Marriott PJ, Munro DD, Ryan T. Angioma serpiginosum familial incidence. Br J Dermatol 1975: 93: 701-706.

McIntosh NAA. Lindau's disease in five generations. Ann Hum Genet 1957: 22: 7-11.

Mercer RD, Rothner AD, Cook SA, Alfidi RJ. The Cobb syndrome. Association with hereditary cutaneous hemangiomas. Cleve Clin Q 1978: 45: 237-240.

Merlob P, Papier CM, Klingberg MA, Reisner SH. Incidence of congenital malformations in the newborn, particularly minor abnormalities. Communication No. 8 to 9th Conference of the European Teratology Society, Basel, Switzerland, 1981.

Merlob P. Reisner SH. Familial nevus flammeus of the forehead and Unna's nevus. Clin Genet 1985: 27: 165-166.

Mitchels VV, Dobyns WB, Groover RV, Mokri B, Forbes GS, Laws ER. Familial cavemous angiomas of the central nervous system and retina. Clin Genet 1985: 37: A69.

Mulliken JB. Capillary (port-wine) and other telangiectatic stains. In: Mulliken JB, Young AE, eds. Vascular birthmarks, hemangiomas and vascular malformations. Philadelphia: W. B. Saunders Company, 1988: 170-195.

Nakagawa H, Furuta $Y$, Nakajima S, Murasawa A, Nakajima $Y$. Surgical excision of familial cavernous angioma in the pontomedullary region. Case report. Neurol Med Chir (Tokyo) 1990: 30: 422-427.

Nova HR. Familial communicating hydrocephalus, posterior cerebellar agenesis, mega cisterna magna, and port-wine nevi. Report on five members of one family. J Neurosurg 1979: 51: 862-865.

Osburn K, Schosser RH, Everett MA. Congenital pigmented and vascular lesions in newborn infants. $J$ Am Acad Dermatol 1987: 16: 788-792.

Pasyk KA, Cherry GW, Grabb WC, Sasaki GH. Quantitative evaluation of mast celis in cellularly dynamic and adynamic vascular malformations. Plast Reconstr Surg 1984a: 73: 69-75.

Pasyk KA, Argenta LC, Erickson RP. Familial vascular malformations. Report of 25 members of one family. Clin Genet 1984b: 26: 221-227.
Pasyk KA. Classification and clinical and histopathological features of haemangiomas and other vascular malformations. In: Ryan TJ, Cherry GW eds. Oxford: Oxford University Press, 1987: 1-54.

Pasyk KA, Wlodarczyk SR, Jakobczak MM, Kurek M, Aughton DJ. Familial medial telangiectatic nevus. Variant of nevus flammeus (port-wine stain). In preparation.

Pratt AG. Birthmarks in infants. Arch Dermatol Syph 1953: 67: 302-305.

Riley HD, Smith WR. Macrocephaly, pseudopapilledema and multiple hemangiomata: A previously underscribed heredofamilial syndrome. Pediatrics 1960: 26: 293-300.

Rook A. Naevi and other developmental defects. In: Rook A, Wilkinson DS, Ebling FJG, eds. Textbook of dermatology. London: Blackwell Scientific Publications. 1972: 138.

Rosen S, Smoller BR. Port wine stains: a new hypothesis. J Am Acad Dermatol 1987: 17: 164-166.

Schnyder UW. Zur Klinik und Histologie der Angiome. 2. Mitteilung: die Feuermaler (Naevi teleangiectatici). Arch Dermatol Syph 1954: 198: 51-74.

Selmanowicz VJ. Nevus flammeus of the forehead. J Pediatr 1968: 75: 755-757.

Shafer J, Doig A. The "Nape naevus". Br Med J 1955: i: 913.

Shelley WB, Livingood CS. Familial multiple nevi flammei. Arch Dermatol Syph 1949: 59: 343-345.

Shuper A, Merlob P, Garty B, Varsano I. Familial multiple naevi flammei. J Med Genet 1984: 21: 112-113.

Smoller BR, Rosen S. Port wine stains. A disease of altered neural modulation of blood vessels? Arch Dermatol 1986: 122: $177-179$.

Snead OC III. Acker JD, Morawetz R. Familial arteriovenous malformation. Ann Neurol 1979: 5: 585-587.

Tabor S, Wyatt EH. Blue-rubber-bleb naevi (report of a family in which only males were affected). Br J Dermatol 1970: 82: 37.

Tan KL. Nevus flammeus of the nape, glabella and eyelids: A distribution, and association with congenital anomalies. Clin Pediatr 1972: 11: 112-118.

Trell E, Johansson BS, Linell F, Ripa J. Familial pulmonary hypertension and multiple abnormalities of large systemic arteries in Osler's disease. Am J Med 1972: 53: 50-63.

van Baar $H$, Perret CM, Happle $R$. Nuchal nevi flammei and alopecia areata. (Letter). Dermatologica 1989: 179: 52-53.

Watson WJ, Thorp JM, Seeds JW. Familial cystic hygroma with normal karyotype. Prenat Diagn 1990: 10: 37-40.

Wertelecki W, Superneau DW, Blackburn WR, Varakis JW. Neurofibromatosis, skin hemangiomas and arterial disease. Birth Defects: Orig Article Series 1982: 18, 3B: 29-41.

Wilkin JK, Montgomery JH, Rosenberg EW. Bilateral, nonsymmetric dermatomal nevi flammei. Arch Dermatol 1979: 115: 1252-1253.

Zaremba J, Stepien M, Jelowicka M, Ostrowska D. Hereditary neurocutaneous angioma: a new genetic entity? J Med Genet 1979: 16: 443-447.

Zonana J, Rimoin DL, Davis DC. Macrocephaly with multiple lipomas and hemangiomas. J Pediatr 1976: 89: 600-603.

Zumkeller R. A propos de la fréquence et mode d'hérédité du "Naevus vasculosus nuchae" (Unna). J Genet Hum 1957: 6: 1. 